\title{
Políticas de saúde integral da população LGBTQI+
}

\author{
Comprehensive health policies for \\ the LGBTQI+
}

\section{Ricardo Araújo da Silva}

Escola Bahiana de Medicina e Saúde Pública (Salvador). Bahia, Brasil. ricardosilva@bahiana.edu.br

Cuidados em saúde com a população LGBTQI+: Você está capacitado(a)?* Iniciamos esse artigo com uma pergunta importante na área da saúde. Quanto estão capacitados(as) nossos(as) profissionais para o atendimento da população de Lésbicas, Gays, Bissexuais, Transexuais, Travestis, Queer e Interssexo? A relevância se dá, pois desde o ano 2009 já existem Portarias e Politicas no SUS que determinam um olhar mais criterioso voltado para atuação profissional nessa esfera. ${ }^{1}$

Algumas publicações demonstram em sua estruturação crítica que o Brasil é um dos países que mais discriminam grupos LGBTQI+ no mundo. Os dados alarmantes impressionam quanto à "LGBTQI+fobia" e os danos causados a essa população, seja por discriminação de gênero ou despreparo dos profissionais dos setores de educação e saúde, que implicam aviltamento dos direitos fundamentais a partir da Constituição Brasileira de 1988, além de desfechos negativos à saúde, inclusive a morte. ${ }^{2-\underline{6}}$
A população LGBTQI+ está inserida em contextos de vulnerabilidade e alvos de forte estigma social. Entretanto, historicamente, nos estudos de gênero, identifica-se uma exclusão de sua situação e, mais ainda no campo da saúde, constata-se pouca investigação sobre os riscos a que essa população é continuamente submetida. Observa-se que o estigma e a discriminação contribuem para o alijamento no contexto social e, consequentemente, a riscos de infecções sexualmente transmissíveis (ISTs), a exemplo do HIV/aids, sífilis, hepatites virais, dentre outras. $\underline{6}$

Adicionalmente, as travestis e pessoas transexuais são mais atingidas pela falta de acesso a serviços de saúde, o que contribui para o aumento do uso, sem supervisão, de técnicas e medicamentos para a modificação corporal não recomendadas pelos conselhos de saúde. Sendo o uso inapropriado do silicone líquido industrial (SLI) e de hormônios femininos e/ou masculino não prescritos considerados fatores que podem estar associados ao aumento das infecções e riscos à saúde nesta população. ${ }^{-1}-9$

\footnotetext{
* A Escola Bahiana de Medicina e Saúde Pública implantou, desde 2018, sob a coordenação do Componente Curricular Saúde Coletiva III do curso de odontologia, um simpósio anual sobre saúde da população LGBTQI+
} 
Em 2013, o Ministério da Saúde Brasileira lançou a política Nacional de saúde integral de lésbicas, gays, bissexuais, travestis e transexuais com o objetivo de promover a saúde integral desta população, eliminando a discriminação e o preconceito institucional, bem como contribuindo para a redução das desigualdades e a consolidação do SUS como sistema universal, integral e equitativo. Passados oito anos somos ainda o país que mais mata e discrimina pessoas LGBTQI+ no mundo. A politica também salienta alguns pontos que urgem celeridade pelo SUS a exemplo de: exame de próstata para mulheres transexuais, exames de colo de útero para homens trans, amplitude de acesso a serviços para toda população LGBTQI+, dentre outros. $\cdot$

Da mesma forma, destaca-se a importância do uso e respeito ao nome social de pessoas trans como forma de diminuir as barreiras à saúde. "O nome carrega junto ao corpo os múltiplos sentidos de feminilidade e masculinidade que operam como constituintes do gênero". .6 Além disso, segundo os autores, a modificação do nome e do gênero nos pronomes de tratamento tornam-se elementos que se entrelaçam nas transformações corpóreas. Para além do setor da saúde, o nome social aparece também como elemento importante na garantia de direitos ao/à cidadão/ã. Podemos usar, como exemplo, uma ação civil pública realizada no Estado do Paraná que teve por objeto o uso do nome social para menores de 18 anos em instituições escolares. A parte interessada foi o Grupo Dignidade. Tal parecer (02/2014) evidencia a necessidade do uso do nome social nos registros escolares, apesar de a legislação brasileira salientar que são relativamente incapazes os menores de 18 anos e os maiores de 16 anos. Assim, quando falamos sobre o direito ao "processo transexualizador" ou de modificação corporal, que implica a terapia hormonal cruzada, ficam implícitos o papel e a responsabilidade do Estado, pois, na história ocidental, o domínio do corpo passou a ser tutelado pelo Estado, que define as suas regras. Logo, os danos causados pela não implantação de políticas públicas de gênero, especificamente as políticas para pessoas trans, são de sua responsabilidade. ${ }^{1}$
Lésbicas, gays, bissexuais, travestis, transexuais e transgêneras têm necessidades específicas de saúde. A orientação sexual e a identidade de gênero são determinantes sociais da saúde, a exemplo da persistência da homofobia e da heteronormatividade como fontes de preconceitos e discriminação. Pessoas LGBTQI+ reportam frequentemente experiências de discriminação em serviços de saúde. ${ }^{10}$

O cuidado prestado, desde o acolhimento e a recepção de grupos LGBTQI+ pelos profissionais de saúde no SUS está relacionado com o nível de conhecimento e compreensão por eles das políticas de saúde preconizadas. Os princípios e diretrizes do SUS no Brasil são claros quanto à universalização, ao cuidado e à integralidade do serviço. O nome social, a adequação do gênero por meio de cirurgias transexualizadoras, ou de adaptações corpóreas na população de travestis e transexuais, fazem parte do reconhecimento do Estado democrático da pluralidade das diversas comunidades e da legitimidade do direito destes segmentos à cidadania. ${ }^{1}$

Por fim, dentro dessa perspectiva das normas e do domínio dos corpos, percebe-se uma ineficiência do Estado como provedor da saúde. Políticas públicas de saúde implantadas não significam, muitas vezes, o entendimento das representações, ou de quem representa o Estado, no âmbito da saúde, da execução e regulação dessas normas.

\section{Conflitos de interesses}

Nenhum conflito financeiro, legal ou político envolvendo terceiros (governo, empresas e fundações privadas, etc.) foi declarado para nenhum aspecto do trabalho submetido (incluindo, mas não se limitando a subvenções e financiamentos, participação em conselho consultivo, desenho de estudo, preparação de manuscrito, análise estatística, etc.).

\section{Referências}

1. Silva RA. Fatores associados às mudanças corporais de travestis e mulheres transexuais, em uma cidade do Nordeste brasileiro [tese]. Salvador: Universidade Federal da Bahia; $2020.164 \mathrm{f}$. 
2. Brasil. Constituição, 1988. Constituição da República Federativa do Brasil. Brasília: Senado Federal; 1988.

3. Carvalho M, Carrara S. Em direito a um futuro trans?: contribuição para a história do movimento de travestis e transexuais no brasil. Sex, Salud S (Rio J). 2013;14(2):319-51. https://doi.org/10.1590/S1984-64872013000200015

4. Maciel IM. Panorama brasileiro do processo transexualizador no âmbito do SUS [monografia] [Internet]. Salvador: Universidade Federal da Bahia; 2017. Disponível em: https://docplayer.com. br/55580633-Panorama-brasileiro-do-processo-transexualizadorno-ambito-do-sus.html

5. Pelúcio L. "Toda quebrada na plástica": corporalidade e construção de gênero entre travestis paulistas. Campos. 2005;6(12):97-112. http://dx.doi.org/10.5380/cam.v6i0.4509

6. Rocon PC, Rodrigues A, Zamboni J, Pedrini MD. Dificuldades vividas por pessoas trans no acesso ao Sistema Único de Saúde. Ciênc saúde colet. 2016;21(8):2517-25. https://doi. org/10.1590/1413-81232015218.14362015
7. Amorim SMG, Vieira FS, Brancaleoni AP. Percepções acerca da condição de vida e vulnerabilidade à saúde de travestis. Saúde debate [Internet]. 2013;37(98):525-35. Disponível em: https://www.scielo.br/j/sdeb/a/TGPHp6LG7nSF8MbxqhSVBJc/ abstract/?lang=pt

8. Trigo LGG. Travesti: prostituição, sexo, gênero e cultura no Brasil. Cad Saúde Pública. 2008;24(9):2195-6. https://doi. org/10.1590/S0102-311X2008000900029

9. Ministério da Saúde (Brasil). Política Nacional de Saúde Integral de Lésbicas, Gays, Bissexuais, Travestis e Transexuais [Internet]. Brasília: Ministério da Saúde. Disponível em: https://bvsms.saude. gov.br/bvs/publicacoes/politica_nacional_saude_lesbicas_gays.pdf

10. Müller A. Teaching lesbian, gay, bisexual and transgender health in a South African health sciences faculty: addressing the gap. BMC Med Educ. 2013;13(1):174. https://doi. org/10.1186/1472-6920-13-174 